\title{
OPERATING ROOM AND PATIENT SAFETY: AN OVERVIEW
}

\section{By}

\section{WAEL MORSY A.EL-SAYED ${ }^{1^{*}}$, ISMAIL ELSAID M. M. ELDEEB ${ }^{1}$,} MAI KHATER A. KHATER ${ }^{1}$ and TOSSON A. MORSY ${ }^{2 * *}$

Military Medical Academy, Cairo, $11291^{1}$ and Faculty of Medicine, Ain Shams University ${ }^{2}$, Cairo, 11566, Egypt ( ${ }^{*}$ Correspondence:w_el_sayed@hotmail.com, \& "morsyegypt2014@gmail.com or tossonmorsy@ tossonmorsy@med.asu.edu.eg)

\section{Abstract}

Safety in the operating room (OR) has always been a major public health concern. It refers to the safety of both the patient and the working personnel. Improving patient safety is an increasing priority for surgeons and hospitals as sentinel events can be catastrophic for patients, caregivers, and institutions. Although patient safety in the operating room (OR) has improved in last decades, significant risks remain. Adverse events may be subtle and delayed (as a central line-associated bloodstream infection due to poor hand hygiene) or dramatic and immediate (e.g., a fire). All operating room personnel must have certain knowledge and skills to provide safety and quality care to patients before, during and after surgery. Review focused on the science of safety principles and efforts to improve safety in the OR.

\section{Introduction}

Surgical and anesthetic safety has improved significantly in the last few decades. Examples of important safety advances include surgical techniques, technology for patient monitoring such as pulse-oximetry to prevent hypoxemia, and fail-safe systems as pinindexing systems for gas cylinders and lines to prevent delivery of hypoxic gas mixtures. Teamwork between anesthesiologists, surgeons, and nurses also improved the operating room safety. But, operating room (OR) environment continues to have significant safety risks for patients, as well as health care providers who work there.

Scientific safety tools (WHO, 2019): Patient Safety is a health care discipline that emerged with the evolving complexity in health care systems and resulting rise of patient harm in health care facilities. It aimed to prevent and reduce risks, errors and harm that occur to patients during provision of health care. A cornerstone of discipline was continuous improvement based on learning from errors and adverse events. Patient safety is fundamental to delivering quality essential health services. Indeed, there is a clear consensus that quality health services across the world should be effective, safe and peoplecentered. Also, to realize the benefits of quality health care, health services must be timely, equitable, integrated, \& efficient. To en- sure successful improvement of patient safety strategies; clear policies, leadership capacity, data to drive safety improvements, skilled health care professionals and effective involvement of patients in their care, are all needed.

Systems Engineering Initiative for Patient Safety (SEIPS): One model of work system design for patient safety is the Systems Engineering Initiative for Patint Safety (SEIPS) (Carayon et al, 2006). This model was anchored in the discipline of human factors engineering and describes the five major components of a health care system: 1-Tasks, 2Personnel, 3-Tools \& technologies, 4- Physical environment, \& 5- Organization.

\section{Review and Discussion}

In the Systems Engineering Initiative for Patient Safety model, the interactions of these five components drive the performance of care processes and safety and quality practices that determine patient, staff, and organizational outcomes. When one component of a care system is changed, it can have a positive or negative effect upon the other components, processes, and outcomes of the system (Carayon et al, 2005).

Safe system design: The science of safety requires recognition that everyone makes mistakes. Well-designed systems must be in place to prevent mistakes, make them visible, and reduce harm should the mistake oc- 
cur. As an example, it is important to document allergies to antibiotics before administering prophylactic antibiotics to a surgical patient. A well-designed system for allergy documentation incorporates two drug allergy checks by two different people, independent of each other.

Safe system design is based upon 3 principles applied to technical work \& team work:

Standardization: Standardization reduces variability, and in turn reduces errors. As an example, all medical gas equipment manufacturers have standardized their equipment with unique connectors for oxygen lines $\&$ nitrous oxide lines, which adds reliability and safety via standardization and is one of the best safe design examples of the OR technical work (Haynes et al, 2011).

Checklists: A checklist creates independent verification for critical steps in work process (Weiser et al, 2010). Examples of checklists were care for placement of central lines, and for preoperative briefing. The comprehensive preoperative assessment was the tool that can be used to identify, document, and communicate patient risk factors or vulnerabilities. Risk assessment anticipates the potential positive $\&$ negative consequences the patient experienced related to anesthesia \& surgical procedure (Poldermans et al, 2008). The nurse asks complete name and birthday, check identification bracelet and compared with records, surgical consent, history and physical examination, surgical site marking, blood, urine \& stool specimens, $\mathrm{x}$ rays, both anesthesia and nurse interviews.

Learning from errors: Clinicians often engage in "first order" problem solving by using a temporary fix or work-around to solve a pressing clinical problem. While a temporary fix may solve the problem for one patient, clinicians must employ "second order" problem solving processes in order to reduce risk to future patients. Second order problem solving requires examination and analysis of the event to identify problems and design systems that defend against future harm (Kavanagh, 2017).
When things went wrong, the following questions should be asked: 1- What happened? 2- Why did it happen? 3- What can do to reduce the risk?, and 4-How to prove that this risk was reduced?

The science of safety is based on understanding that teams make wiser decisions when there is diverse and independent input. This means that input from all team members was considered, including patients, parents, and all clinicians involved in a patient's care. Patients and their families add experiential knowledge, but clinicians offer discipline-specific knowledge. A culture of safety allowed all team members to feel comfortable and encouraged to voice their concerns without fear of retribution or criticism, regardless their position on the team (Surowiecki, 2004).

Comprehensive unit-based safety program (CUSP): A comprehensive unit-based safety program (CUSP) made safety and quality a permanent part of a clinical group's mission by fostering active communication, teamwork, and collaboration (Timmel et al, 2010). As culture varied widely among units within a hospital, CUSP was implemented at the unit or clinical area level with a multidisciplinary team composed of physicians, nurses, administrators, and other staff. CUSP not only identified problems and works toward solutions, but also it tapped into many people wisdom and can be a major force for cultural change that sustained and reinforced the patient safety initiatives (Pronovost et al, 2005). This program proved effective in risky environments, such as the ITU, and was widely used in many different clinical areas, including the OR (Holzmueller et al, 2009). The CUSP program included five main components (Nakre and Harikiran, 2013):

1- Education: All staff must be educated on science of safety. Boccanfuso and Kuhfeld, (2011) reported that physical safety referred to the protection of all stakeholders, including families, caregivers, students, school sta$\mathrm{ff}$, and the community, from violence, theft, and exposure to weapons and threats to esta- 
blish a secure learning environment. They added that for students to learn, they need to feel safe. It was essential that students have the opportunity to attend schools that must provide a safe environment where they can thrive and fully engage in studies without distraction and worry about physical safety concerns.

2- Identify hazards: Staff members are asked to identify defects in their clinical area (Silva et al, 2016). CUSP encourages staff to proactively ask: How will team harm next patient? This strategy uncovers hazards that were unique to a care area and empowers staff in that area to mitigate them (Klidas et al, 2007).

3- Administrative support: A senior executive is partnered with a unit to actively support local efforts. This bridges the division between administrators and frontline staff (nurses, doctors, pharmacists, \& others), and provides a mechanism to voice safety concerns directly to hospital administration. Besides, a senior executive on the local CUSP team ensures there are requisite resources for work, holds team accountable to reduce risks, and informs senior leadership of patients' safety hazards (Klevens et al, 2007).

Regular meetings: CUSP teams meet regularly to review safety issues, investigate and identify defects, and design safer systems of care. To be effective, defects are prioritized to determine which ones will have the greatest impact on safety and quality and be the most feasible to implement. Apart of this process, factors contributing to and mitigating defects are analyzed and rated for their importance. A one-page summary report from this learning from defect process was generated and shared broadly throughout the organization. Yang et al. (2014) in USA reported that massive sensor data could support identification of secondary crashes. Occurrence mechanism of the secondary crashes was studited by the proposed model. They added that to understand mechanism helped deploy appropriate countermeasures to mitigate or prevent the secondary crashes.
4- Implementation: Tools such as briefings, $\&$ debriefings were implemented to facilitate communication and teamwork and establish a culture of safety in the OR (Makary et al, 2006). While operating room briefing formats vary, essential components included an introduction of names and roles, a review of key checklist items (e.g., giving antibiotics), any safety concerns of team members, and a contingency plan for risks during operation. Another useful tool is shadowing, in which one type of clinician (e.g., resident) follows another (e.g., nurse) for several hours, and then discusses how they worked differently now that they have walked in another's professional shoes (Thompson et al, 2008).

5- Teamwork: Team training is a useful method of improving a communication. As an example, a teamwork training program, team STEPPS (Team strategies and tools to enhance performance and patient safety), was implemented at many hospitals worldwide (Weaver et al, 2010). In the USA, the Agency for Healthcare Research \& Quality was implementing teamSTEPPS training nationwide (Stead et al, 2009). TeamSTEPPS study of training on trauma resuscitation team performance showed meaningful improvement of care efficacy for patients in a level 1 trauma center. Compared with pre-training performance (convenience sample of 33 patients), teams' post-training performance (40 patients) showed significant decrease in the time from arrival to the CT scanner was 26 to 22 minutes, time to intubation was 10 to 6.6 minutes and time to OR was 130 to 94 minutes (Capella et al, 2010). The strategies to reduce errors and subsequent adverse outcomes focused on team and individual training: simulations, and drills; development of protocols, guidelines, and checklists; using information technology, and education (Kohn et al, 1999). The activities and tools were applied to inpatient and office settings (Erickson et al, 2010). As failures in team-work and communication account for $70 \%$ of sentinel events in obstetrics, in a labor and delivery setting, the mother and her baby were 
not cared for solely by her obstetric providers, but also by nurses, anesthesia and pediatric providers, \& support staff. Formal teamwork training was increasingly as a part of the orientation of new hospital staff members, with the goal of improving teamwork and communication (Birnbach and Salas, 2008).

Informed surgical consent: Physicians have a legal and ethical responsibility to provide adequate information to the patient so patient would able to the information processing and made appropriate decisions. The SEIPS model is a patient safety approach based on an industrial engineering subspecialty of human factors, although emphasis was placed on interactions within the work system to include the person, organization, tools and technology, tasks, and environment $(\mathrm{Ca}-$ rayon, 2006). He added that customers' contribute significantly to the co-production of products/services, as well as to their quality/safety. The sociotechnical systems design collaborated with both workers in the systems and customers required increased attention not only to the design and implementation of systems, but also to continuous adaptation and improvement of systems in the collaboration with customers. The team STEPPS was a research generic program (King, 2008). Aaberg et al. (2021) in Norway reported on 5 key principles: 1- Team structure and 4 team competencies "leadership", "situation monitoring", "mutual suport" and "communication". The 4 team competencies of team-STEPPS have 15 associated tools and strategies that implemented in clinical practice to improve performance and patient safety (Stewart et al, 2015). 2- Team decision making was an additional team competency or team process (Salas et al, 2014), not included in team STEPPS program, but included in the study as it was an important aspect of team-work with significance for patient safety \& patient care (Reader, 2017). Also, Zavala et al. (2018) in Australia added that research from other areas of hospitals showed that most clinical decisions still made independently by the medical professionals with only some shared information, and decisions were rarely made collectively by an inter-professional care team.

Task of securing an informed consent from the patient must be done before any invasive procedures are started or any blood or blood products administered.

Personnel: Surgeon or surgical resident doing the procedure should carry out this task that involves more than just getting a patient's signature. It involved explaining risks, benefits, and alternatives to procedure using language that was clearly understood by the patient, so that he or she can make an informed decision before signing the consent.

Tools: Tools such as fully vetted consent forms that use clear and unambiguous language could ensure a true informed patient consent. Informed consent has medicolegal and ethical ramifications. This document is equally important for the care team because it gave a road map of actions the patient expects, assuming that patient understand the risks, benefits, and alternatives.

Physical environment: Environment may adversely affect this process. Sometimes informed consent was done immediately before surgery in a public area (e.g., outside the OR), in which the surrounding distractions may coerce a patient to consent without fully comprehending information described. But, the anesthesiologist's or sometimes the surgeon's initial introduction to the patient often happened shortly before going to the OR.

Organization: The culture that clearly known the informed consent process, the value this document brings to the care team, and the protection it provides for the patient, will ensure that this task achieves its goal.

Using a checklist for preoperative briefing: A preoperative briefing should be done with the entire OR team including the surgeon, anesthesiologist, circulating nurse, and scrub technician. Briefings standardized the teamwork, can lower staff anxiety over the unknown, and improve organizational culture. The briefing process anticipates risks, which helps staff perform better and recover 
from a situation should it occur (Smith et al, 2008). A study of a 19 item surgical safety check-list in 1750 patients undergone urgent surgery showed a significant decrease in death rates (1.4 vs. $3.7 \%)$ and complication rates $(11.7$ vs. $18.4 \%)$ after the checklist implementation. Also, implementation of checklist significantly increased adherence to $6 \mathrm{se}-$ lected safety measures from 18.6 to $50.7 \%$. The use of this checklist was adopted by the WHO. Available at the WHO site safe surgery saves Lives: www.who.int/patientsafety/ safe-surgery/en/index.html.

The preoperative briefing was standardized and should include the following elements: 1- Team introductions and roles, 2- Reidentification of patient identity and consent, the surgery or procedure to be done, and site, side or level as in tables $(1,2,3, \& 4), 3$ - Patient positioning, padding, and skin preparation, 4- Equipment, instrument, or implant concerns. Team should verify that the necessary equipment is present and working, 5Appropriate monitoring strategies, 6- Goals and critical steps of the procedure, with contingency plans, 7- Blood product availability, 8- Identification of likely pathology specimens, \& 9- Post-operative disposition (post anesthesia care unit versus ICU).

Correct patient, site, \& procedure: Practicing safe, high-quality OR care begins with accurately identifying patient, surgical site, and procedure (Guglielmi et al, 2010). The USA Joint Commission sentinel event statistics database reported that wrong site surgery was the most frequently reported serious adverse event from 1995 to 2010, accounted for 666 of 4850 sentinel events was $13.7 \%$ (The Joint Commission, 1996). But, the reporting of sentinel events to the Joint Commission was voluntary and represented only a portion of actual events, with a systematic review found that rate of wrong site surgery varied from 0.09 to $4.5 / 10,000$ surgeries performed (Neily et al, 2009). Factors that contributed to wrong site surgery include incorrect patient positioning, poor communication, incorrect or lack of patient consent, failure to use site markings, surgeon fatigue, multiple surgeons, multiple procedures on same patient, bad time pressures, emergency operations, \& unusual patient anatomy.

Tasks: Accurate identification of patient, surgical site, and procedure. In cases where an anesthesia block preceded the surgical intervention, identification of surgical site and procedure must be done by both anesthesia team and surgical team.

Personnel: Dual identifiers or two different providers (usually a nurse $\&$ physician) must independently confirm they have the correct patient, site, and procedure. To be effective, however, the checks must be truly independent. Two clinicians verifying identifiers or other information together was not an independent check because individuals commonly encode each other's errors.

Tools: Hospitals typically use technical tools such as plastic wrist bands or stamp cards to identify patients, but these may be accidentally removed or lost. The commonest method to identify the correct operative site was to mark it with an indelible marker or dye when the correct patient was verified. If the site was not marked at that time, it should be done using the independent check process to ensure the correct site marked.

Physical environment: Sometimes, physical environment obscures wristband (e.g., arms tucked under the patient on the OR table). In this setting, a second band could be placed on a more visible part of the body.

Organization: Organization culture support independent checks reduced errors. The correct procedure is confirmed in OR at the start of a briefing or time-out by asking patient what he or she expected to have done.

Infection control: There was a significant risk for surgical site and central line associated infections associated with the OR.

Surgical site infections (SSI) were common complications of the OR procedures. SSIs are more common in contaminated or dirty wounds than in clean or clean-contaminated wounds. Other risk factors such as diabetes, 
obesity, and smoking contribute to SSIs. Risk factors for SSIs were combined into a predictive model called the National Healthcare Safety Network risk index. Wound classification and other risk factors for SSI are discussed in detail elsewhere.

On average, an SSI doubles the cost of a patient's healthcare, mainly by increasing the length of patient's hospital stay (Broex et $a l, 2009)$. Several interventions such as appropriate antibiotic prophylaxis and maintenance of normothermia can reduce the risk of the SSIs. The 5 components of preventing surgical site infection according to the syste $\mathrm{ms}$ engineering initiative for patient safety model (Gagliardi et al, 2009):

Tasks: Antibiotic prophylaxis was a recommended preoperative practice, and appropriate antibiotics and timing of administration for different surgical procedures given in evidence-based guidelines (Casey and Elliott, 2009). This task involves administering the first dose at least 10 minutes, but $<60$ minutes, before incision to obtain adequate tissue levels of antibiotics. Avoiding hypothermia reduces SSI rates (Sessler, 2009). Also, impaired thermoregulation can affect drug metabolism and impair platelet function. The importance of maintaining normothermia during recovery led to the mandate from the Joint Commission and Surgical Care Improvement Project (SCIP) to warm patients to $36^{\circ} \mathrm{C}$ within 15 minutes of arrival in post-anesthesia care unit (Mauermann and Nemergut, 2006). Warming in the operating room and the PACU can be achieved using circulating water garments or forced air warming devices (Galvão et al, 2010). Although elevating the temperature of the operating room can reduce temperature gradient and reduce heat loss from the patient, there is no standard target thermostat setting in the operating room. Temperature of the pediatric OR must be usually maintained at a higher setting compared with OR for adult surgery, since children can lose heat faster due to the larger surface-to-volume ratio in children. However, the need to maintain normotherm- ia in the patient must be balanced by the ability of operating room personnel to function given that heavy impervious surgical gowns may result in profuse sweating that may lead to dehydration and/or inadvertent wound contamination.

Personnel: Anesthesiologist is responsible for antibiotics administering and managing normothermia. But, these tasks required effective communication among team members. For maintaining normothermia, the anesthesiologist must balance the need to maintain normothermia in the patient with comfort of the operating room staff. Modern forced-air systems to warm patient allowed for this balance to be maintained fairly easily.

Tools: Preprinted schedules help to ensure repeated dosing of antibiotics when indicated. Warming blankets and fluid and blood warming devices must be readily available. Modern forced warm air devices proved effective at maintaining patient's temperature while allowing the OR team to maintain a comfortable working environment.

Physical environment: OR environment, including cold OR tables, cold air convection currents in theater, \& cold IV fluids, increased a patient's risk of hypothermia.

Organization: The organization must suport the teamwork necessary for the timely administration of antibiotics and maintenance of normothermia as well as providing the appropriate tools and technologies.

Central line infection: Central lines are often placed in the OR as a potential source of postoperative infection. The 5 components of preventing central line infections after the Systems Engineering Initiative for Patient Safety model were listed.

Tasks: Clear evidence demonstrated that most central line-associated infections were preventable if the following checklist was used to ensure the completed behaviors (Berenholtz et al, 2004): 1- Wash hands prior to procedure, 2- Use full barrier protection (sterile gowns, glove, hats, \& full body drapes), 3- Use chlorhexidine to prepare skin site, 4Avoid using femoral site for central line pla- 
cement, \& 5- Remove catheters when no longer indicated.

Personnel: The anesthesiologist inserting the central line in the OR must adhere to the behaviors on the checklist.

Tools: A central line insertion checklist should be used as a guide.

Physical environment: The anesthesiologist must be provided with the time to insert central lines safely and appropriately.

Organization: Effective teamwork and an organizational culture that supports infection reduction are both vital. OR staff should be empowered to alert the anesthesiologist or surgeon if they forget to wash their hands or if a guide-wire accidentally touches the anesthesia circuit and becomes contaminated.

Needle-stick injuries: Needle-stick injuries and injuries from other sharp objects were common throughout the hospital setting and were a constant risk in the OR (Abdel-Motagaly et al, 2017). But, its' incidence was reduced by advances in education, needle disposal, engineering changes (e.g., needleless devices, safety needles) \& worker protection, institutions and the healthcare authorities must continue to assume responsibility for more lowering the risk.

Nosocomial infection: In Egypt Morsy (2012) found indoors bloodsucking \& crawled insects. Also, nosocomial HDM (Saleh et $a l, 2913$ ) and nosocomial myiasis (Morsy, 2014) were reported. Judson and Munster (2019) in USA found that nosocomial transmission of emerged \& re-emerged viruses, bacterial and parasitic diseases highlighted risk in healthcare settings. Maltezou et al. (2019) in Greece stated that vaccinations of healthcare workers aimed to directly protect them from occupational acquisition of vaccine-preventable diseases and to indirectly protect patients and the essential healthcare infrastructure.

Anesthesia: Improvements in the safety of anesthesia administration have decreased the incidence of perioperative myocardial infarction, neurological injuries, and mortality. Much of this improvement was attributed to better medications, equipment, and monitoring tools and other technology. International standards for anesthesia safe practice were established by the WHO (Merry et al, 2010). These comprehensive standards detail recommendations for training and accreditation, record keeping, equipment, patient evaluation, intra-operative monitoring and postoperative care. The 5 components of safe anesthesia administration after the Systems Engineering Initiative for Patient Safety model were listed.

Task: Safe anesthesia administration after the international standards of care.

Personnel: Anesthesiologist, nurse anesthetist, anesthesia assistants.

Tools: Monitoring tools as pulse oximetry and scenography were widely credited with improved OR safety. Improved monitoring provides early warning of adverse events, and prevented patient harm (Merry et al, 2010). Pulse oximetry monitored blood for adequate oxygen delivery. Scenography showed whether alveolar ventilation was established to reduce the chance of an unrecognized esophageal intubation.

Physical environment: Adequate and appropriate equipment and facilities, should be present wherever anesthesia and recovery is provided. Anesthesia equipment must conform to relevant national and international standards (Pronovost et al, 2010).

Organization: The organization must support the anesthesiologists and anesthesia care team, by providing proper equipment and a culture of teamwork within the anesthesia team, within the surgeons and nursing staff.

Protecting patients from injury in OR: Patients must be transferred and positioned properly in the OR. Moreover, patients and OR personnel must be protected from electrical, thermal, or radiologic injury in the OR (Nishiyama et al, 2010).

Proper positioning: Positioning of patient is required to avoid pressure sores, nerve compression, deep vein thrombosis, and compartment syndrome (Adedeji et al, 2010).

Task: Prevent injury to patients by giving 
proper positioning during surgery.

Personnel: Nursing staff, surgeons, \& anesthesia personnel must work together to ensure proper patients' positioning for surgery.

Tools: Equipment to prevent injury such as gel pad, pillows, or axillary or chest rolls must be available.

Physical environment: A correct OR table with appropriate attachments must be available and in good working order. Moving the patient must be done in a coordinated fashion and sliding boards or roll boards must be used for patients who cannot move themselves. Restraints must be secure, but not too tight or placed over superficial nerves or bony prominences.

Organization: The OR staff must be educated about the correct equipment and procedures to optimize patient positioning and avoid injuries during surgery.

Electrical injury: Electrical injury can lead to muscle contraction, respiratory paralysis, seizures, or lead to ventricular fibrillation and also dissipated energy throughout the tissues and increases the temperature of tissue, which could produce burns or cause cellular death (Barker and Doyle, 2010). Grounding of power supplies is necessary to prevent electrical injury. An ungrounded or "floating" power supply must be monitored with a line isolation monitor (LIM). A LIM monitors the integrity of a power supply and alarms when it was not grounded properly. Five components of preventing electrical injury in OR after the Systems Engineering Initiative for Patient Safety model were listed.

Task: Prevent electrical injury to patients and personnel in the OR by using a LIM.

Personnel: All OR personnel are responsible for knowing how the LIM works and what to do if the alarm sounds.

Tools: A line isolation monitor (LIM) must be used to quickly recognize to prevent an electrical injury.

Physical environment: OR is purposefully isolated from the ground unit and the OR equipment is ungrounded to add protection against an electrical shock. With this config- uration, two faults must exist before a patient was shocked. If one fault occurs, the electrical current can leak to ground, thereby removing one layer of protection. So, LIM monitors the flow of electricity from the OR to the ground and sounds an alarm when it detects a leak.

Organization: Team must quickly work together to unplug the most recently connected equipment and work backwards until the alarm terminates, then remove that item for inspection by Clinical Engineering.

Thermal injury: As many as 100 OR fires occur per year in the United States, resulted in 1 to 2 deaths/year though numbers may be higher due to under-reporting (Frantz and Byers, 2011). Skin preparation and antiseptic solutions and anesthetic gases can cause fires in OR. Most surgical fires occur in the airway (34\%) and head or face (28\%) fires (Rocos and Donaldson, 2011).

Task: Prevent thermal injury to patients and staff in the operating room.

Personnel: All OR personnel are responsible for preventing a fire.

Tools: Water based skin preparations exist but are less commonly used because they take up to 15 minutes to dry and must be fully dry to be effective. Faster drying alcohol based preparations, take only 3 minutes to dry on bare skin. However, if applied to hair bearing areas, alcohol based skin preparations may take as much as an hour to dry, causing in a prolonged flammability period. So, alcohol based skin preparations should be avoided for hair bearing areas and when an oxygen-enriched environment is required, as in head and neck surgery. Briefings and checklists can define whether adequate drying time has occurred.

The oxygen must be set at a safe minimum (usually 30\% FIO2), and fire retardant technologies must be used if possible. As an example, endotracheal tubes made of less flammable materials or metal reduce the risk of fire during an airway surgery and should be considered in high risk cases. Briefings and checklists can define whether it was approp- 
riate to minimize oxygen, ensure appropriate equipment was used, and define the case risk environment.

Physical environment: OR thermal injury is fire that always a concern when local concentrations of oxygen are high, when flammable materials and gases were used, or when ignition source (e.g., cautery) was used. For cases where flammable gastrointestinal gases may cause a hazard, use of cautery should be avoided. As for example, to avoid an explosion during gastrointestinal surgery, the bowel opening must be made with a scissors or scalpel. Once the gas is released, it will be safe to use cautery to extend the incision.

Organization: The organization must educate staff and establish policies to prevent thermal injuries or mitigate harm in case of fire. Simulation exercises can effectively prepare personnel to control a fire, protect the patient, and reduce the panic that OR fires can engender should they occur, despite robust prevention strategies. Fire suppress-ion systems must also be in place but sprinklers can contaminate the surgical field and halontype systems are not feasible with personnel in room (Le Heron et al, 2010).

Radiation injury: Radiation injury is rarely immediate like a burn or shock and because of this is often under-rated. In fact, this adverse outcome most often manifests after long periods of time. Even very low levels of radiation exposure have stochastic (random) biologic effects that were cumulative and permanent (Chaffins, 2008). Probability of radiation injury increases with increasing cumulative exposure to radiation (Sheyn et al, 2008). Task-prevent radiation injury to patients and team in OR.

Personnel: Staff must adhere to the principles of keeping the radiation dose as low as reasonably allowable, minimizing radiation exposure, and meeting regulatory guidelines.

Tools: Radiation barriers must be provided for all OR personnel. Besides, OR personnel must wear radiation dosimeters (tools) to track exposures.

Physical environment: The U.S. Regulatory Commission limits a person's radiation exposure to $5000 \mathrm{mrems} / \mathrm{year}$, and the CDC limits fetal exposures to 500mrems during an entire pregnancy. To ensure that guidelines were met, the US Health and Human Services' Office of Health \& Safety investigated radiation doses that exceed $125 \mathrm{mrems}$ to whole body or $>1875 \mathrm{mrems}$ to extremities in a given quarter year. Also, corrective action was required if radiation exposures exceed $>375 \mathrm{mrem} /$ quarter to whole body or $>5625 \mathrm{mrem} /$ quarter to extremities.

Organization: Minimizing or preventing exposure relied heavily upon education, teamwork, and an organizational culture that consistently uses radiation barriers and dosimeters.

Connection errors: Connection errors, or misconnections, and wrong infusions, are infusions of the wrong medication or gas into the wrong place (McAfee et al, 2010). For example, intravenous medications have been injected into the epidural space and gas has been infused into the bloodstream. This resulted from Luerlock fittings, connectors $\&$ locks that make different brands of tubing compatible. While Luerlocks were convenient and crease a microbiologically closed system, contributed to inadvertent errors connection (Simmons et al, 2008). No amount of vigilance or local safety culture can prevent all medication errors or connection errors. But, education about Luerlock misconnections along with increasing standardization in the types of infusion devices, the drug names, concentrations and dosing limits can decrease errors (Fraind et al, 2002):

Task: Ensure proper infusion of medications and gases.

Personnel: The anesthesia \& nursing staff.

Tools: Tasks of preparing, labeling, administering, documenting, and disposing of drugs must be stream-lined to help OR personnel avoid errors. Rapid and reliable access to drugs, supplies and equipment must be provided. Intravenous drugs must be provid- 
ed in clearly identified, ready to administer packaging at the care point. Infusion devices and drug choices should be limited and standardized (Arora et al, 2010).

Physical environment: Dynamics in OR environment place tremendous stress on its staff, making mistakes inevitable. Distractions, fatigue, multi-tasking, and time pressures deplete a person's ability to remain vigilant and consistently defend against poorlydesigned systems led to mistakes. A study of stressors in OR demonstrated that technical problems, patient, equipment problems, and teamwork problems were stressful factors for surgeons (Kötter et al, 2017).

Organization: It was challenging to uncover a consistent cause of errors and, even if found, to provide a consistent viable solution that minimizes the chances of a recurrent event. By recognizing untoward events occur, learning from them, and working to prevent them, patient safety can be improved minimizing medication errors and connection errors requires a multi-disciplinary approach, organizational support for infusion devices standardization \& drug choices (Oyebode, 2013)

A postoperative debriefing was used to identify and learn from mistakes/defects occured during procedure with the purpose to improve care and preventing the next patient from being harmed. But, it was relatively easy to identify hazards in debriefings; it was more difficult to ensure reduced risks (Papaspyros et al, 2010). OR team must create an organizational system and process to collect issues identified in debriefings, prioritize them, and implement interventions to reduce these risks. The debriefing checklist must: 1Ensure all paperwork was properly labeled with the patient's name and medical record number, 2- Complete specimen forms for pathology, 3- Did any equipment problems occur that need to be investigated?, 4- What must be done to have safer or more efficient proce-dure?, \& 5- Discuss patient transition from OR to post-operative care unit or ICU, as to fluid management, antibiotics, tests/ $\mathrm{x}$ rays, pain control, medications, blood glucose control, and ongoing DVT prophylaxis.

Table1: American Society of Anesthesiologists physical status scale

\begin{tabular}{|c|l|}
\hline Class I: & A normal healthy individual \\
\hline Class II: & A patient with mild to moderate systemic disease \\
\hline Class III: & A patient with severe systemic disease that limits activity but is not incapacitating \\
\hline Class IV: & A patient with incapacitating systemic disease that is a constant threat to life \\
\hline Class V: & A moribund patient who is not expected to survive 24 hours with or without operation \\
\hline Class VI: & A clinically dead patient being maintained for harvesting organs \\
\hline ASA - E: & Emergent operations \\
\hline
\end{tabular}

Table 2: JCAHO protocol for surgical timeout

\begin{tabular}{|l|l|}
\hline $\begin{array}{l}\text { Perform a preoperative verification } \\
\text { process (ideally with patient awake, } \\
\text { aware and involved) }\end{array}$ & $\begin{array}{l}\text { Ensure that all relevant documents and studies available prior to start } \\
\text { procedure. Identify patient with at least two patient identifiers (e.g., name, } \\
\text { sex, mobile No). }\end{array}$ \\
\cline { 2 - 3 } & $\begin{array}{l}\text { Ensure reviewed information and internally consistent as well as consistent } \\
\text { with patient's expectations and with surgical team's understand intended } \\
\text { patient, proced- ure, site \&, as applicable, any implants. }\end{array}$ \\
\cline { 2 - 3 } & $\begin{array}{l}\text { Missing information or discrepancies must be addressed before starting } \\
\text { surgery }\end{array}$ \\
\hline $\begin{array}{l}\text { Mark operative site to unambiguous- } \\
\text { ly identify intended procedure site }\end{array}$ & $\begin{array}{l}\text { For procedures involving right/left distinction, multiple structures (as fingers } \\
\text { \& toes), or multiple levels (as in spinalones), intended site must be marked. } \\
\text { Ideally surgeon in charge mark site. A procedure must be defined for patients } \\
\text { who refuse site marking. }\end{array}$ \\
\cline { 2 - 2 } & $\begin{array}{l}\text { Mark must be unambiguous (e.g., use initials or "YES" or a line representing } \\
\text { planned incision; "X" may be ambiguous). Mark must be visible after patient } \\
\text { prepped and draped (e.g., use a permanent marker). Non-operative sites must } \\
\text { not be marked. }\end{array}$ \\
\hline $\begin{array}{l}\text { Take a time pre-procedure to condu- } \\
\text { ct correct a verification patient, pro- } \\
\text { cedure, site \&, applicable, implants }\end{array}$ & $\begin{array}{l}\text { Procedure is not started until any questions or concerns are resolved and all } \\
\text { members of the surgical/procedure team are in agreement. Identify the patient } \\
\text { with at least two patient identifiers. }\end{array}$ \\
\hline
\end{tabular}


Table 3: Timing of prophylactic antibiotic administration and subsequent rates of SSI

\begin{tabular}{|c|c|c|c|}
\hline Administration time & Surgical site infection \% (SSI) & Odds ratio (logistic-regression) & CI 95\% \\
\hline Early & 3.8 & 4.3 & $1.8-10.4$ \\
\hline Preoperative & 0.6 & 1.0 & - \\
\hline Perioperative & 1.4 & 2.1 & $0.6-7.4$ \\
\hline Postoperative & 3.3 & 5.8 & $2.4-13.8$ \\
\hline
\end{tabular}

Table 4: General recommendations for prevention of infections associated with any intravascular catheter in patients

\begin{tabular}{|l|l|}
\hline $\begin{array}{l}\text { Healthcare worker } \\
\text { education \& training }\end{array}$ & $\begin{array}{l}\text { Educate healthcare workers regarding indication for intravascular catheter use, proper } \\
\text { procedu-res for insertion, maintenance, and infection control to prevent intravascular } \\
\text { catheter-associated infections }\end{array}$ \\
\hline Hand hygiene & $\begin{array}{l}\text { Observe proper hand hygiene either by washing hands with conventional antiseptic- } \\
\text { containing soap and water or with waterless alcohol-based gels or foams. Use of gloves } \\
\text { does not obviate need for hand hygiene. }\end{array}$ \\
\hline $\begin{array}{l}\text { Aseptic technique during } \\
\text { catheter insertion \& care }\end{array}$ & $\begin{array}{l}\text { Maintain aseptic technique for insertion and care of intravascular catheters. Use } \\
\text { maximal barrier precautions when inserting arterial or central venous catheters }\end{array}$ \\
\hline Catheter site care & $\begin{array}{l}\text { Disinfect clean skin with an appropriate antiseptic before catheter insertion and at time } \\
\text { of dressing changes. 2\% Chlorhexidine-based preparation preferred but no } \\
\text { recommendation for its use in infants less than two months of age. }\end{array}$ \\
\cline { 2 - 3 } & Use sterile gauze or sterile transparent semipermeable dressing to cover tcatheter site. \\
\cline { 2 - 3 } & $\begin{array}{l}\text { Do not use topical antibiotic ointment or creams on insertion sites (except for dialysis } \\
\text { catheters). }\end{array}$ \\
\hline Intravascular catheters & Remove any intravascular catheter that is no longer essential. \\
\hline Replacement of \\
administration sets & $\begin{array}{l}\text { Replace administration sets, including secondary sets and add-on devices, no more } \\
\text { frequently than at 72hrs intervals, unless clinically indicated. Replace tubing used to } \\
\text { administer blood, blood products, or lipid emulsions within 24hrs of initiating infusion. } \\
\text { Replace tubing used to give propofol infusions every } 6 \text { to 12hrs, based on its use by } \\
\text { manufacturer's recommendation }\end{array}$ \\
\hline Parenteral fluids & Complete infusion of lipid containing solutions within 24hrs of hanging the solution. \\
\cline { 2 - 2 } & Complete infusion of lipid emulsions alone within 1hr of hanging the solution. \\
\cline { 2 - 3 } Complete infusions of blood or other blood products within4hrs of hanging the blood \\
\hline Intravenous injection & Clean injection ports with 70\% ethanol or an iodophor before accessing the system. \\
\hline
\end{tabular}

\section{Conclusion and Recommendations}

1-OR poses significant safety risks to patients and the health care providers.

2- Systems Engineering Initiative for Patient Safety model describes the five major components of a health care as tasks, personnel, tools and technologies, physical environment and organization. Interactions of these five components drive the performance of care processes, safety and quality practices that determine patient, staff, and organizatonal outcomes.

3- Patient safety can be improved by bringing scientific principles to health care practice. Safe system design is built upon the principles of standardization, checklists, and learning from errors.

4- CUSP makes safety and quality a permanent part of a clinical group's mission by OR.

9- Surgical site infection rates are reduced with appropriate antibiotic prophylaxis and maintenance of normothermia. fostering active communication, teamwork, and collaboration. CUSP program included education, identification of hazards, adminiistrative support, regular meetings and implementation.

5- Physicians have a legal and ethical responsibility to provide adequate information to the patient so the patient is able to process information and make appropriate decisions. 6- A preoperative briefing with a checklist be performed with entire OR team including the surgeon, anesthesiologist, circulating nurse, and scrub technician before proceeding with surgery (Grade 1C).

7- Using dual identifiers to identify the patient, surgical site, and procedure before proceeding with surgery (Grade 1C).

8- A significant risk for surgical site \& central line associated infections associated with 10- Central line infection rates can be reduced with handwashing, full barrier protection, proper skin preparation, avoidance of the 
femoral site, and removal of catheters when they are no longer indicated.

11- Patients must be transferred and positioned properly in OR. Also, patients and OR personnel must be protected from electrical, thermal, or radiologic injury in OR.

12- A line isolation monitor (LIM) should be used to ensure quick recognition and prevention of electrical injury.

13- Alcohol based skin preparations should be avoided for hair bearing areas and when an oxygen-enriched environment is required, as in head and neck surgery.

14- Oxygen must be set at a safe minimum (usually $30 \% \mathrm{FIO} 2$ ), and fire retardant technologies should be used if possible.

15- Radiation doses must be kept as low as reasonably allowable to minimize radiation exposure and meet regulatory guidelines.

16- Connection errors and infusions of wrong medication or gas into wrong place decreased by standardizing the types of infusion devices, the drug names, concentrations and dosing limits.

17- A postoperative debriefing to identify $\&$ learn from mistakes/defects that occurred du ring the procedure to improve care, and pre venting next patient from being harmed.

\section{References}

Aaberg, OR, Hall-Lord, ML, Husebo, SIE, Ballangrud, R, 2021: A human factors intervention in a hospital- evaluating the outcome of a TeamSTEPPS program in a surgical ward. BMC Hlth. Serv. Res. 21: 114. doi: 10.1186/ s12913-021-06071-6

Adedeji, R, Oragui, E, Khan, W, Maruthainar, N, 2010: The importance of correct patient positionning in theatres and implications of malpositioning. J. Perioper. Pract. 20:143-50.

Abdel-Motagaly, AME, Ibrahim, AMA, Morsy, TA, 2017: An intervention program on blood protozoa acquired by needle stick injury and infection control. J. Egypt. Soc. Parasitol. 47, 2: 309-22

Arora, S, Hull, L, Sevdalis, N, et al, 2010: Factors compromising safety in surgery: stressful events in the operating room. Am. J. Surg. 199: 60-6.

Barker, SJ, Doyle, DJ, 2010: Electrical safety in the operating room: Dry versus wet. Anesth.
Analg. 110:1517-20.

Berenholtz SM, Pronovost PJ, Lipsett PA, et al, 2004: Eliminating catheter-related bloodstream infections in the intensive care unit. Crit. Care Med. 32:2014-9.

Birnbach, DJ, Salas, E, 2008: Can medical simulation and team training reduce errors in labor and delivery? Anesthesiol. Clin. 26:15964.

Boccanfuso, B, Kuhfeld, M, 2011: Multiple responses, promising results: Evidence-based, nonpunitive alternatives to zero tolerance. Washington, DC: Child Trends

Broex, EC, van Asselt, AD, Bruggeman, CA, van Tiel, FH, 2009: Surgical site infections: how high are the costs? J Hosp. Infect. 72:193-9. Capella, J, Smith, S, Philp, A, et al, 2010: Teamwork training improves the clinical care of trauma patients. J. Surg. Educ. 67:439-43.

Carayon, P, 2006: Human factors of complex sociotechnical systems. Appl. Ergon. 37, 4:52535

Carayon, P, Hundt, AS, Alvarado, CJ, et al, 2005: Implementing a systems engineering intervention for improving safety in outpatient surgeries. In: Advances in Patient Safety: From Research to Implementation, Henriksen $\mathrm{K}$, Battles JB, Marks ES, Lewin DI. (Eds.): Agency for Healthcare Research and Quality (US), Rockville, MD, Vol. 3.

Carayon, P, Schoofs, HA, Karsh, BT, et al, 2006: Work system design for patient safety: the SEIPS model. Qual. Saf. Hlth. Care 15, 1:i50-8.

Casey, AL, Elliott, TS, 2009: Progress in the prevention of surgical site infection. Curr. Opin. Infect. Dis. 2:370-8.

Chaffins, JA, 2008: Radiation protection and procedures in the OR. Radiol. Techn. 79:415-20.

Erickson, TB, Kirkpatrick, DH, DeFrancesco, MS, Lawrence, HC $3^{\text {rd, 2010: Executive }}$ summary of the American College of Obstetricians and Gynecologists Presidential Task Force on Patient Safety in the Office Setting: Reinvigorating safety in office-based gynecologic surgery. Obstet. Gynecol. 115:147-50.

Fraind, DB, Slagle, JM, Tubbesing, VA, et al, 2002: Reengineering intravenous drug and fluid administration processes in the operating room, step one: Task analysis of existing processes. Anesthesiology 97:139-43.

Frantz, K, Byers, CG, 2011: Thermal injury. Compend. Contin. Educ. Vet. 33, 12:E1.

Gagliardi, AR, Eskicioglu, C, McKenzie, M, 
et al, 2009: Identifying opportunities for quality improvement in surgical site infection prevention. Am. J. Infect. Control 37:398-402.

Galvão, CM, Liang, Y, Clark, AM, 2010: Effectiveness of cutaneous warming systems on temperat- ure control: Meta-analysis. J. Adv. Nurs. 66:1196-9.

Guglielmi, C, Canacari, E, Moorman, D, et al, 2010: Strategies for preventing wrong site, wrong procedure, wrong patient surgery. AORN J, 92:22-9.

Haynes, AB, Weiser, TG, Berry, WR, et al, 2011: Changes in safety attitude and relationship to decreased postoperative morbidity and mortality following implementation of a checklistbased surgical safety intervention. BMJ. Qual. Saf. 20:102-9.

Holzmueller, CG, Timmel, J, Kent, PS, et al, 2009: Implementing a team-based daily goals sheet in a non-ICU setting. Jt. Comm. J. Qual. Pat. Saf. 35:384-90.

Judson, SD, Munster, VJ, 2019: Nosocomial transmission of emerging viruses via aerosol-generating medical procedures. Viruses 11, 10: 940-8.

Kavanagh, C, 2017: Medication governance: Preventing errors and promoting patient safety. Br. J. Nurs. 26, 3:159-65

King, HB, 2008: Team Strategies and Tools to Enhance Performance and Patient Safety. In: Henriksen K, et al, eds. Advances in Patient Safety: New Directions and Alternative Approaches (Vol. 3: Performance \& Tools) Rockville: US Agency for Healthcare Research and Quality.

Klevens, RM, Edwards, J, Richards, C, Horan, T, Gaynes, R, et al, 2007: Estimating health care-associated infections \& deaths in US. Hospitals, 2002; Publ. Hlth. Rept. 122:160-6.

Klidas, A, van den Berg, PT, Wilderom, CP M, 2007: Managing employee empowerment in luxury hotels in Europe. Intern J. Serv. Indus. Manag.18, 1:70-88

Kohn, LT, Corrigan, JM, Donaldson, MS, 1999: Committee on Quality of Health Care in America, Institute of Medicine. To Err Is Human: Building a Safer Health System. Washing ton, DC.

Kötter, T, Wagner, J, Brüheim, L, Voltmer, E, 2017: Perceived medical school stress of undergraduate medical students predicts academic performance: An observational study. BMC Med. Educ. 17, 1:256. doi: 10.1186/s12909-017.
Le Heron, J, Padovani, R, Smith, I, Czarwinski, R, 2010: Radiation protection of medical staff. Eur. J. Radiol. 76:20-6.

Makary, MA, Holzmueller CG, Thompson D, et al, 2006: Operating room briefings: working on the same page. Jt. Comm. J. Qual. Pat. Saf. 32:351-8.

Maltezou, HC, Theodoridou, K, Ledda, C, Rapisarda, V, Theodoridou, M, 2019: Vaccination of healthcare workers: Is mandatory vaccination needed? Expert. Rev. Vacci.18, 1:5-13.

Mauermann, WJ, Nemergut, EC, 2006: The anesthesiologist's role in the prevention of surgical site infections. Anesthesiology 105:413-20.

McAfee, N, Seidel, K, Watkins, S, Flynn, JT, 2010: A continuous quality improvement project to decrease hemodialysis catheter infections in pediatric patients: Use of a closed luer-lock access cap. Nephrol. Nurs. J. 37:541-8.

Merry, AF, Cooper, JB, Soyannwo, O, Wilson, IH, Eichhorn, JH, 2010: International standards for a safe practice of anesthesia 2010. Cana. J. Anaesth. 57, 11:1027-34.

Morsy, TA, 2014: Insect bites and what is eating you? J. Egypt. Soc. Parasitol. 42, 2: 291308.

Morsy, TA, 2014: Zoonotic myiasis in Egypt: With reference to nosocomial or hospital-acquired myiasis. J. Egypt. Soc. Parasitol. 44, 3:63952.

Nakre, PD, Harikiran, AG, 2013: Effectiveness of oral health education programs: A systematic review. J. Int. Soc. Prev. Comm. Dent. 3, 2:103-15.

Neily, J, Mills, PD, Eldridge, N, et al, 2009: Incorrect surgical procedures within and outside of the operating room. Arch. Surg. 144:1028-32.

Nishiyama, K, Komori, M, Kodaka, M, Tomizawa, Y, 2010: Crisis in the operating room: fires, explosions and electrical accidents. J. Artif. Organs. 13:129-34.

Oyebode, F, 2013: Clinical errors and medical negligence. Med. Princ, Pract. 22, 4:323-33.

Papaspyros, SC, Javangula, KC, Adluri, RK, O'Regan, DJ, 2010: Briefing and debriefing in the cardiac operating room: Analysis of impact on theatre team attitude and patient safety. Interact. Cardiovasc. Thorac. Surg. 10:43-8.

Poldermans, D, Hoeks, SE, Feringa, HH, 2008: Pre-operative risk assessment and risk reduction before surgery. J. Am. Coll. Cardiol. 51, 20:1913-24 
Pronovost, P, Weast, Rosenstein, BJ, Sexton, JB, 2005: Implementing and validating a comprehensive unit-based safety program. J. Pat. Saf. 1:33-40.

Pronovost, PJ, Holzmueller, CG, Martinez, E, et al, 2006: A practical tool to learn from defects in patient care. Jt. Comm. J. Qual. Patient Saf. 32:102-8.

Pronovost, PJ, Goeschel, CA, Colantuoni, E, et al, 2010: Sustaining reductions in catheter related bloodstream infections in Michigan intensive care units: observational study. BMJ 340:c309-12.

Reader, TW, 2017: Team Decision Making. In: Salas E, Rico R, Passmore J, (Eds.) The Wiley Blackwell Handbook of the Psychology of Team Working and Collaborative Processes. West Sussex: Black Wiley.

Rocos, B, Donaldson, LJ, 2012: Alcohol skin preparation causes surgical fires. Ann. R. Coll. Surg. Engl. 94, 2:87-9.

Saleh, AM, Ali, HA, Ahmed, SA, Mohamad, NM, Morsy TA, 2013: Knowledge and performance regarding management of house dust mites in a military hospital. J. Egypt. Soc. Parasitol. 43, 3:821-40.

Salas, E, Cannon-Bowers, JA, Johnston, JH, 2014: In: How can you turn a team of experts into an expert team? Emerging training strategies, in Naturalistic Decision Making. Zsambok, C, Klein, G, (Eds.). NY: Psychology Press.

Sessler, DI, 2009: New surgical thermal management guidelines. Lancet 374:1049.

Sheyn, DD, Racadio, JM, Ying. J, et al, 2008: Efficacy of a radiation safety education initiative in reducing radiation exposure in the pediatric IR suite. Pediatr. Radiol. 38:669-74.

Silva, MJ, Alhowaish, L, Ghanim, A, Manton, DJ, 2016: Knowledge and attitudes regarding molar incisor hypomineralisation amongst Saudi Arabian dental practitioners and dental students. Eur. Arch. Paediatr. Dent. 17, 4:215-22.

Simmons, D, Phillips, MS, Grissinger, M, et al, 2008: Error-avoidance recommendations for tubing misconnections when using Luer-tip connectors: A statement by the USP Safe Medication Use Expert Committee. Jt. Comm. J. Qual. Pat. Saf. 34:299-304.
Smith, HM, Jacob, AK, Segura, LG, et al, 2008: Simulation education in anesthesia traitning: A case report of successful resuscitation of bupivacaine-induced cardiac arrest linked to recent simulation training. Anesth. Analg. 106: 1581-8.

Stead, K, Kumar, S, Schultz, TJ, et al, 2009: Teams communicating through STEPPS. Med. J. Au-st.190:S128-32.

Stewart, GL, Manges, KA, Ward, MM, 2015: Empowering sustained Patient Safety: the benefits of combining top-down and bottom-up approaches. J. Nurs. Care Qual. 30, 3:240-6.

Surowiecki, J, 2004: The Wisdom of Crowds: Why the Many are Smarter than the Few and How Collective Wisdom Shapes Business, Economics, Societies and Nations, $1^{\text {st }}$ ed., Random House, New York.

The Joint Commission, 2011: The Sentinel Event Policy is available online at: http://www. joint commission.org/Sentinel Event Policy /

Thompson, DA, Holzmueller, CG, Lubomski, L, Pronovost, PJ, 2008: View world through a different lens: shadowing another provider. Jt.

Comm. J. Qual. Pat. Saf. 34:614-8.

Timmel, J, Kent, PS, Holzmueller, CG, et al, 2010: Impact of the comprehensive unit-based safety Program (CUSP) on safety culture in a surgical inpatient unit. Jt. Comm. J. Qual. Pat. Saf. 36:252-9.

Weaver, SJ, Rosen, MA, DiazGranados, D, et $\boldsymbol{a l}, 2010$ : Does teamwork improve performance in the operating room? a multilevel evaluation. Jt. Comm. J. Qual. Pat. Saf. 36:133-9.

Weiser, TG, Haynes, AB, Dziekan, G, et al, 2010: Effect of a 19-item surgical safety checklist during urgent operations in a global patient population. Ann. Surg. 251:976-80.

WHO, 2019: Patient Safety: Global action on patient safety. Report by the Director-General.

Yang, H, Ozbay, K, Xie, K, 2014: Assessing the risk of secondary crashes on highways. J.

Safety Res. 49:143-9.

Zavala, AM, Day, GE, Plummer, D, Wade, AB, 2018: Decision-making under pressure: Medical errors in uncertain and dynamic environments. Aust. Hlth. Rev. 42, 4:395-402 